\title{
Erratum
}

\section{Erratum: Feldmann-Wüstefeld et al., "Spatially Guided Distractor Suppression during Visual Search”}

In the article "Spatially Guided Distractor Suppression during Visual Search," by Tobias Feldmann-Wüstefeld, Marina Weinberger, and Edward Awh, which appeared on pages 3180-3191 of the April 7, 2021 issue, there was a labeling error in the bottom row of Figure 4. The labels on the graphs should instead read "Target lateral Difference wave (contra-ipsi)" on the left and "Distractor lateral Difference wave (contra-ipsi)" on the right. This error does not affect the conclusions of the article. The figure has been corrected in the online version.
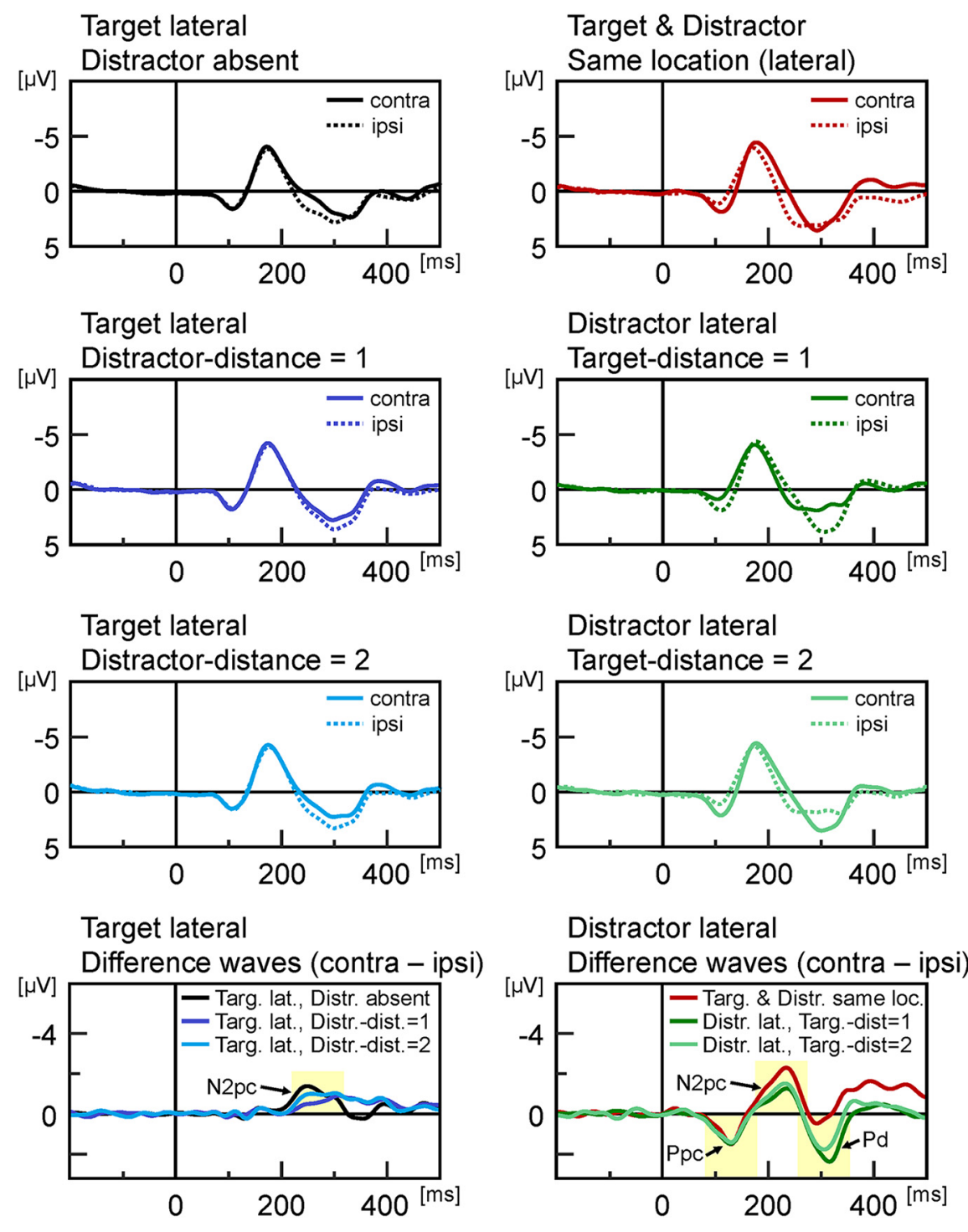

Figure 4. 